\title{
ADSORPTION OF WATER ON THE FINE FRACTIONS OF FINNISH TILLS
}

\author{
AARRE KELLOMÄKI and PERTTI NIEMINEN
}

\begin{abstract}
KELLOMÄKI, AARRE and NIEMINEN, PERTTI, 1986: Adsorption of water on the fine fractions of Finnish tills. Bull. Geol. Soc. Finland 58, Part 2, 13-19.

This study deals with adsorption of water from the vapour phase on till samples at $25^{\circ} \mathrm{C}$. The dry weights were determined after drying the samples in an oven at $105^{\circ} \mathrm{C}$. Complete adsorption isotherms were measured for 41 tills with a "desiccator method" using saturated salt solutions as humidity standards. In addition, partial isotherms were determined for about 40 other samples. The isotherms were BET types I and II. The surface areas computed with the BET equation from water adsorption are considerably larger than the nitrogen adsorption areas of the same samples. In order to compare the isotherms with each other they have been presented as film thicknesses against relative humidity. All curves can then be satisfactorily represented by four model isotherms, which reflect the interactions of water molecules and the adsorbent surfaces. To a certain extent the model isotherms correlate with the mineral composition of the samples. Free energies of adsorption were calculated. Their negative values indicate that adsorption is highly exothermic at low humidities, or the samples are hygroscopic.
\end{abstract}

Key words: till, adsorption, water, isotherm, surface area.

Aarre Kellomäki: Department of Biomedical Sciences, University of Tampere, P.O. Box 607, SF-33101 Tampere, Finland.

Pertti Nieminen: Laboratory of Engineering Geology, Tampere University of Technology, P.O. Box 527, 33101 Tampere, Finland.

\section{Introduction}

Till is a sediment stemming from glacial ice. It consists of non-sorted particles of different sizes and of various minerals, and it has more variations in its properties than any other sediment (Goldthwait 1971). Tills are the most common soils in Northern Europe, which was covered by vast glaciers during the most recent ice ages.

In their natural environments tills interact closely with water. Depending on the amount of water and the kind of till, different soil-water systems are formed (Barshad 1955) ranging from fairly dry soils to very wet sols or fluid-like pastes. The properties of such systems are important both in intact nature and when the soil is used for agricultural or civil engineering purposes. In this work we studied the adsorption of water from the gas phase on dried, unpurified till samples. The study is part of a more extensive research project concerning the properties of Finnish tills.

\section{Materials and methods}

Complete adsorption experiments were done for 41 till samples in different states of weathering. Faster measurements with fewer experi- 


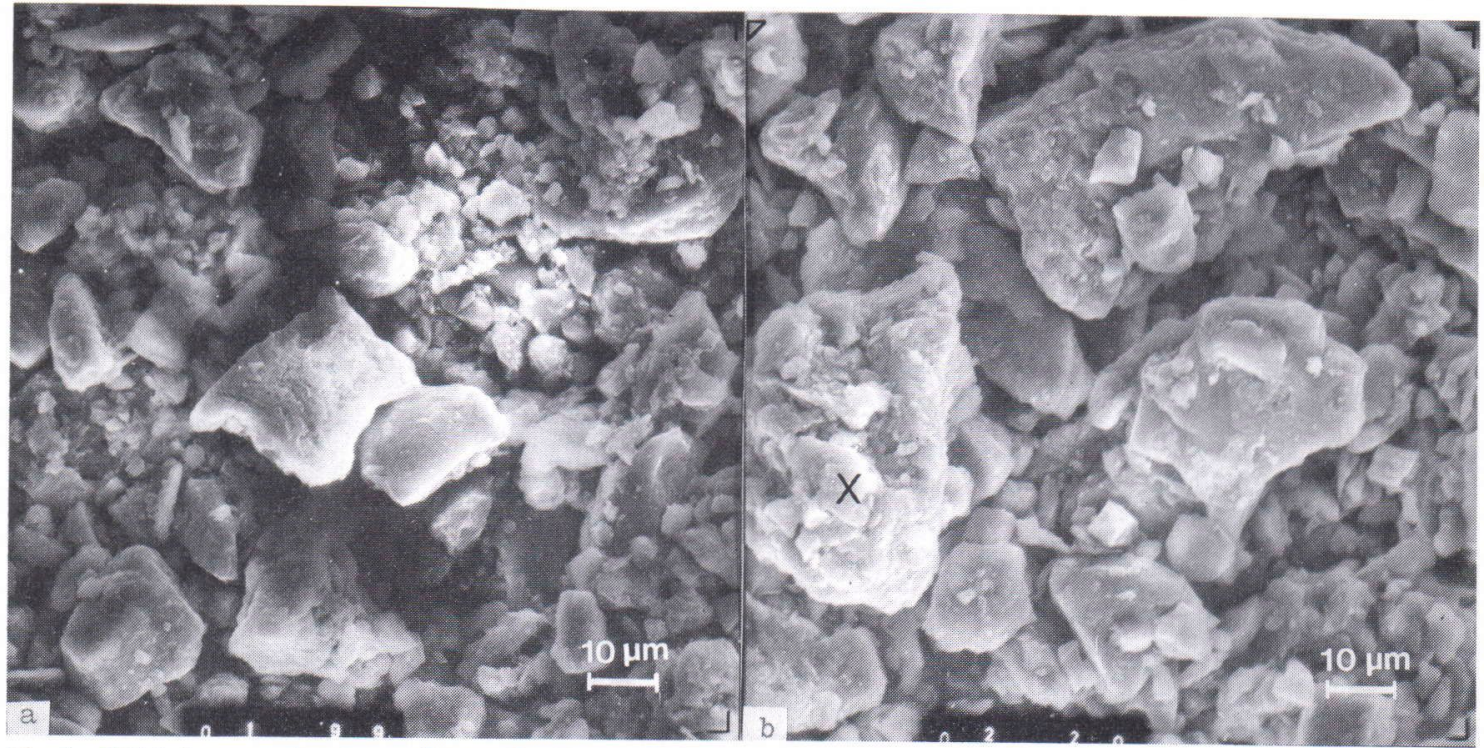

Fig. 1. SEM photographs of two silty sandy tills. Sample $a$ has a type A isotherm and sample $b$ a type B isotherm. Samples $a$ and $b$ had the following properties, respectively: Clay content $(<2 \mu \mathrm{m}) 6.0 \%$ and $8.0 \%$, uptake of water $33.3 \mathrm{~g} / \mathrm{kg}$ and $14.6 \mathrm{~g} / \mathrm{kg}$, water BET area $25,000 \mathrm{~m}^{2} / \mathrm{kg}$ and $15,000 \mathrm{~m}^{2} / \mathrm{kg}$, nitrogen BET area $7,950 \mathrm{~m}^{2} / \mathrm{kg}$ and $5,500 \mathrm{~m}^{2} / \mathrm{kg}$. In Fig. 1 $b$ the $\mathrm{X}$ marks a typical particle covered with organic matter.

mental points were conducted on about 40 other tills. The samples comprised typical Finnish ablation and lodgement tills and related materials. Figure 1 shows examples of their textures. For reference and comparison, some samples of silts, clays and clay minerals were also included in the experiments. The materials used were not purified in any way. Thus, any humus and iron compounds were preserved. As adsorption experiments require homogeneous samples with sufficiently large surface areas, the soils were sieved and fine fractions under $74 \mu \mathrm{m}$, amounting to 13 to $68 \%$ of the total mass of the starting materials, were used in the measurements. All chemicals, such as the salts for the humidity standards, were of analytical grade and were used as received.

The air-dried samples were spread out in thin layers $(0.5$ to $6 \mathrm{~g})$ on tared Petri dishes $(\varnothing 40 \mathrm{~mm})$. They were kept in the oven overnight at $98^{\circ} \mathrm{C}$. The temperature was then raised to $105^{\circ} \mathrm{C}$ for 30 minutes. The hot samples were weighed quickly on an analytical balance and inserted into hu- midistats that, in most experiments, were ordinary desiccators. Some of the experimental runs were, however, carried out in a special humidistat, where the air can be circulated with a magnet-operated paddle stirrer (Kellomäki 1978). The proper relative humidities in the range of 7 to $100 \%$ were obtained with nine saturated salt solutions (Stokes and Robinson 1949; Kellomäki 1978) and with pure water. At the relative humidity of $100 \%$ there was a risk of water condensing inside the lids of the humidistats and causing drops to fall on the samples. This was avoided by inserting the humidistats into a larger thermostated vessel.

The samples were weighed quickly and the weights recorded. Care was taken to disturb the atmosphere of the humidistats as little as possible when opening them. At a given relative humidity, the samples gained constant weights in 2 to 7 days. The salt solution was then replaced with another giving a higher humidity. Some preliminary desorption trials were also conducted, but this simple method is not suitable for such 
studies, and the hysteresis loops remained open even at the relative humidity of $33 \%$.

The nitrogen BET areas of the samples (Brunauer, Emmett and Teller 1938) were measured with a Micromeritics Surface Area Analyzer MIC-2200. JEOL X-ray Diffractometer JDX-7S was used in the X-ray diffraction analyses. The scanning electron micrographs were taken with a JEOL JSM3 SEM instrument, with which microanalysis is also feasible.

\section{Results and discussion}

Details of the experimental data have been published in the report of Tampere University of Technology, Department of Civil Engineering (Nieminen and Kellomäki 1982a). As a summary some typical properties of the tills with complete isotherms are given in Table 1 grouped according to the four model isotherms (see below). The most important findings and the conclusions drawn from them are discussed in the following.

\section{Dry weights}

We found that the "dry weight" of soil is a somewhat arbitrary concept. Drying in vacuo or over concentrated sulphuric acid resulted in excessively high dry weights. On the other hand, results of drying at $105^{\circ} \mathrm{C}$ depend on the drying time: with prolonged heating it is evidently possible to remove from many samples water that surely ought to be included in the dry weights. Some such samples were found to denaturate (Orchiston 1953), that is, their weights in the first half of the isotherm remained a little below those of the more gently dried samples of the same soils. In such cases it was difficult to correct erroneous observation points afterwards with new experiments. Excessively low dry weights were detected by very high or even negative BET $\mathrm{C}$ parameters. More consistent dry weights were then estimated with the aid of analogous isotherms. The gentler mode of drying at $105^{\circ} \mathrm{C}$ described in the 'method' section was found to give reliable dry weights for most samples.

\section{Adsorption isotherms and application of the BET theory}

The adsorption isotherms obtained for till samples in this study resemble those for soils and clay minerals in the literature (Orchiston 1953, 1954, and 1955). Three typical examples are shown in Fig. 2. Some of the isotherms first rise steeply before remaining at a plateau like the BET type I isotherms (Brunauer et al. 1938). Most curves are sigmoidal like the BET type II isotherms of multilayer physical adsorption. Two

Table 1. Some properties of the fine fractions of Finnish tills. The samples have been grouped according to the four model isotherms.

\begin{tabular}{|c|c|c|c|c|c|c|c|c|c|}
\hline \multicolumn{4}{|c|}{ Model isotherms } & \multicolumn{6}{|c|}{ Mean values and standard deviations of the properties } \\
\hline \multirow[t]{2}{*}{ group } & \multicolumn{2}{|c|}{$\begin{array}{c}\text { BET parameters } \\
\text { eq. ( } 2)\end{array}$} & \multirow[t]{2}{*}{$\begin{array}{c}-\Delta \mathrm{G} \\
\mathrm{J}\end{array}$} & \multirow[t]{2}{*}{$\begin{array}{c}\text { number of } \\
\text { samples }\end{array}$} & \multicolumn{2}{|c|}{$\begin{array}{l}\text { percentages } \\
\text { of fine grades }\end{array}$} & \multirow{2}{*}{$\begin{array}{c}\text { uptake of } \\
\text { water at } \\
100 \% \mathrm{R} . \mathrm{H} . \\
\mathrm{g} / \mathrm{kg}\end{array}$} & \multicolumn{2}{|c|}{$\begin{array}{c}\text { BET areas } \\
\mathrm{m}^{2} / \mathrm{kg}\end{array}$} \\
\hline & $\mathrm{C}$ & $\mathrm{z}$ & & & $74 \mu \mathrm{m}$ & $2 \mu \mathrm{m}$ & & $\mathrm{H}_{2} \mathrm{O}$ & $\mathrm{N}_{2}$ \\
\hline A & 75 & 2.8 & 14,000 & 16 & $\begin{array}{r}40 \\
\pm 11\end{array}$ & $\begin{array}{r}5 \\
\pm 2\end{array}$ & $\begin{array}{r}15 \\
\pm 10\end{array}$ & $\begin{array}{r}13,900 \\
\pm 8,900\end{array}$ & $\begin{array}{r}5,400 \\
\pm 3,600\end{array}$ \\
\hline B & 10 & 4.5 & 9,600 & 2 & $\begin{array}{r}18 \\
( \pm 6)\end{array}$ & $\begin{array}{r}4 \\
( \pm 3)\end{array}$ & $\begin{array}{r}30 \\
( \pm 11)\end{array}$ & $\begin{array}{r}21,000 \\
( \pm 19,000)\end{array}$ & $\begin{array}{r}11,000 \\
( \pm 6,100)\end{array}$ \\
\hline $\mathrm{C}$ & 35 & 4.5 & 12,900 & 20 & $\begin{array}{r}41 \\
\pm 10\end{array}$ & $\begin{array}{r}8 \\
\pm 5\end{array}$ & $\begin{array}{r}27 \\
\pm 13\end{array}$ & $\begin{array}{r}18,500 \\
\pm 9,400\end{array}$ & $\begin{array}{r}10,200 \\
\pm 6,000\end{array}$ \\
\hline $\mathrm{D}$ & 90 & 9 & 18,000 & 3 & $\begin{array}{r}35 \\
\pm 19\end{array}$ & $\begin{array}{r}10 \\
\pm 7\end{array}$ & $\begin{array}{r}34 \\
\pm 3\end{array}$ & $\begin{array}{r}14,000 \\
\pm 2,300\end{array}$ & $\begin{array}{r}9,700 \\
\pm 7,500\end{array}$ \\
\hline
\end{tabular}




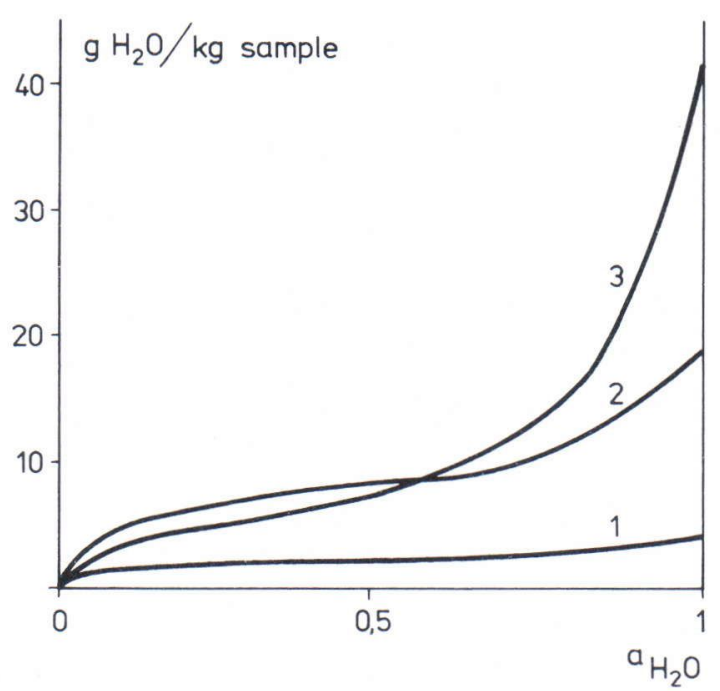

Fig. 2. Three actual adsorption isotherms.

suspected BET type IV isotherms were encountered, but desorption experiments to establish their true nature failed. The isotherms are fairly regular at lower relative humidities, but the variance is wider at relative humiditive above $75 \%$. Some isotherms tend to rise nearly vertically when the saturation humidity is approached, and it was difficult to establish the correct values of the total uptake of water. For the till samples, it ranged from 4 to $57 \mathrm{~g}$ of $\mathrm{H}_{2} \mathrm{O}$ per $\mathrm{kg}$ of dry soil. For weathering materials and clays, values as high as 100 to $200 \mathrm{~g} / \mathrm{kg}$ were measured.

The two parameter BET isotherm (Brunauer et al. 1938; Adamson 1976) was found to represent the observations fairly well at low humidities. This isotherm is given by equation

(1) $\frac{\mathrm{a}}{1-\mathrm{a}} \cdot \frac{1}{\mathrm{n}}=\frac{1}{\mathrm{C} \cdot \mathrm{n}_{\mathrm{m}}}+\frac{(\mathrm{C}-1) \mathrm{a}}{\mathrm{C} \cdot \mathrm{n}_{\mathrm{m}}}$, where

$\mathrm{a}=\mathrm{p} / \mathrm{p}_{\mathrm{o}}=$ activity of water or relative humidity

$\mathrm{n}=$ amount of adsorbed water (here $\mathrm{mol} / \mathrm{kg}$ )

$\mathrm{n}_{\mathrm{m}}=$ amount of water required to form a monolayer

$\mathrm{C}=$ parameter reflecting the magnitude of heat of adsorption.

For most samples, straight lines $a /(1-a) n$

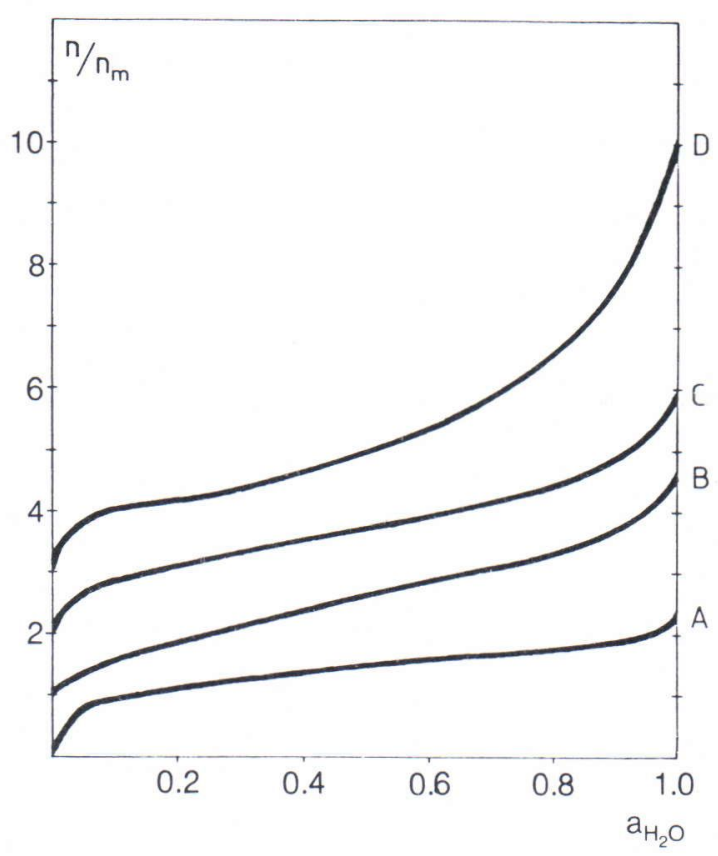

Fig. 3. The four model isotherms. For clarity the zero level of each curve B-D has been lifted.

against a were obtained in the range of $\mathrm{a}=0.07$ to 0.33 . The parameters $\mathrm{C}$ and $\mathrm{n}_{\mathrm{m}}$ were determined by the method of least squares. The values of parameter $C$ were in the range of 15 to 150 . The specific surface areas computed from $n_{m}$ by assigning a cross-sectional area of $0.106 \mathrm{~nm}^{2}$ for a water molecule (Gregg and Sing 1967) were 3,500 to $45,000 \mathrm{~m}^{2} / \mathrm{kg}$. They are several times larger than the nitrogen BET areas (Table 1).

The thickness of the adsorbed water film can be presented by plotting $\mathrm{n} / \mathrm{n}_{\mathrm{m}}$ against $\mathrm{p} / \mathrm{p}_{\mathrm{o}}$. When this was done for the present data, a variety of curves was naturally obtained; however, over $90 \%$ of them can be represented quite satisfactorily by the four model isotherms (Fig. 3 ). They are denoted by letters A to D in the order of increasing film thickness in the middle of the isotherm. The model isotherms first rise like the general BET isotherms (Eq. (1)), but at higher humidities they stay below them. Such behaviour can be explained by assuming that adsorption is restricted, say, to $\mathrm{z}$ molecule layers. The resulting 
adsorption isotherm is presented by the three parameter BET equation (Adamson 1976)

(2) $\frac{\mathrm{n}}{\mathrm{n}_{\mathrm{m}}}=\frac{\mathrm{C} \cdot \mathrm{a}}{1-\mathrm{a}} \cdot \frac{1-(\mathrm{z}+1) \cdot \mathrm{a}^{\mathrm{z}}+\mathrm{z} \cdot \mathrm{a}^{\mathrm{z}+1}}{1+(\mathrm{C}-1) \cdot \mathrm{a}-\mathrm{C} \cdot \mathrm{a}^{\mathrm{z}+1}}$.

where $\mathrm{z}$ is the maximum number of adsorbate layers, and the other quantities are the same as in Eq. (1).

Equation (2) was successfully applied to the model isotherms A to D. Two hours of trials with a personal computer yielded combinations of the parameters that gave close fits of the computed curves with the experimental ones up to the relative humidity of $80 \%$. These parameters are given in Table 1, and thus the lower parts of the isotherms A to D in Fig. 3 have been computed. The parts of the isotherms with R.H. above $80 \%$ were drawn as average of the actual curves. Most till samples have isotherms of types $\mathrm{A}$ and $\mathrm{C}$. Only montmorillonite and two till samples have isotherm B. Isotherm D is also rather rare. The isotherms of clays are of types $\mathrm{C}$ and $\mathrm{D}$. The restriction of adsortion to 2 to 5 water molecule layers must not be taken too literally. According to porosity measurements of the same samples (Nieminen and Kellomäki 1982b), they contain abundant mesopores and macropores larger than tens of water molecule diameters. Thus, the success of Eq. (2) reflects the range of the adsorption forces rather than the true geometric dimensions of the pores. When approaching saturation humidity, the nature of adsorption seems to change, probably because of interlayer expansion (Barshad 1955).

\section{Relationship of the adsorption isotherms and the properties of the samples}

The mineral composition of the samples could be expected to be an important factor in the form of the adsorption isotherms. According to the literature, A-type isotherms with a steep rise at low humidities are obtained if soils contain exchangeable cations, such as $\mathrm{Ca}^{2+}$ or $\mathrm{Mg}^{2+}$, with high heats of hydration (Orchiston 1955). Simi- lar isotherms may also result from adsorption on microporous samples or from chemical adsorption (Gregg and Sing 1967). In this study, electron micrographs showed amorphous iron compounds in many samples with isotherm A. Such compounds are hygroscopic, and the adsorption of the water removed may be partly of chemical nature, already taking place at low humidities. With respect to the amounts of organic matter, there were no significant differences between samples of different isotherm types. The isotherms are clearly correlated with neither the hydraulic conductivities nor the sieve curves of the samples, although particle size distribution is generally believed to be a major factor in many properties of powdered materials. The till samples with A isotherms have, however, smaller average clay contents and a smaller total uptake of water than the other samples. Specific surface areas computed from water adsorption are approximately similar for all isotherm classes, and they are considerably higher than the areas computed from nitrogen adsorption. The differences between the two areas are particularly big in the case of the A isotherm where water is strongly bound.

\section{Free energies of adsorption}

The spontaneity of the adsorption can be concluded from the Gibbs energy change taking place during it. $\Delta \mathrm{G}_{\text {ads }}$ was calculated using the following equation (Gregor et al. 1952; Barshad 1960; Kellomäki 1978):

(3) $\Delta \mathrm{G}_{\mathrm{ads}}=-\mathrm{RT} \int_{0}^{1} \frac{\mathrm{n}}{\mathrm{a}} \mathrm{da}$.

Here $\mathrm{n}$ is the number of water molecules adsorbed at water activity a, $\mathrm{R}$ is the gas constant, and $\mathrm{T}$ the absolute temperature. The integral is best evaluated with graphic integration by plotting $\mathrm{n} / \mathrm{a}$ against a. This can already be started at the lower limit, as, according to the BET equation (1), $\lim _{\mathrm{a} \rightarrow 0} \mathrm{n} / \mathrm{a}$ is equal to $\mathrm{Cn}_{\mathrm{m}}$ (Kellomäki 1978). The calculations were done using Simpson's equation. The amounts of water adsorbed 


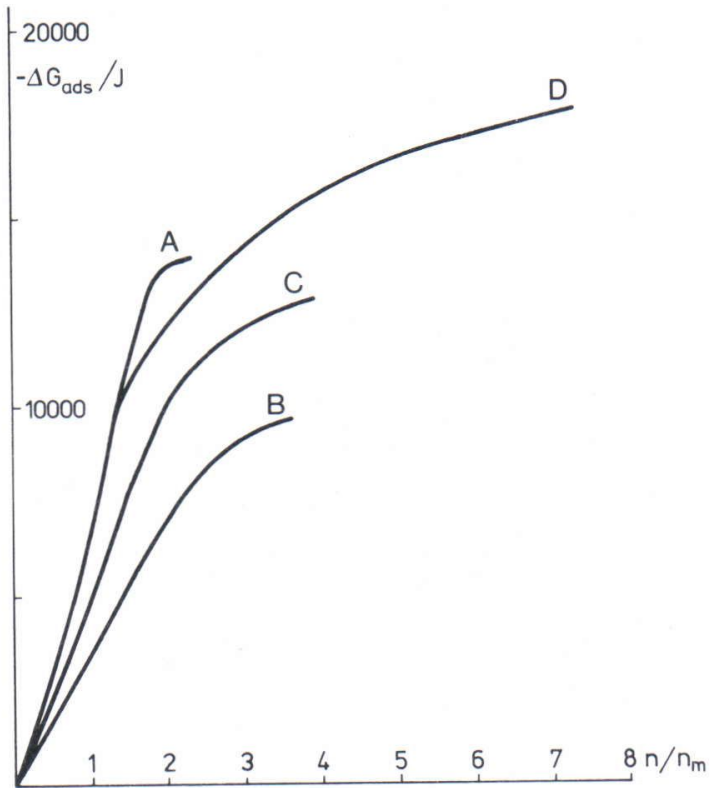

Fig. 4. Free energies of adsorption for the model isotherms referring to adsorption of $n / n_{m}$ moles of water on soil.

at successive activity intervals of 0.05 were taken from isotherms drawn on a large scale.

The Gibbs energies for the model A to D isotherms referring to the adsorption of $n / n_{m}$ moles of water on soil are presented in Fig. 4 and Table 1. These values depend heavily on the BET $\mathrm{C}$ parameter or on the heat of adsorption; a large portion of the free energy is due to the steep initial rise at which the sample is hygroscopic. The actual Gibbs energies of adsorption, including the effect of different surface areas, were -1070 to $-7340 \mathrm{~J} / \mathrm{kg}$ in 21 till samples. The variance is caused by the differences in water adsorption, not by the isotherm types.

\section{The nature of the water monolayer}

The sorption of polar water molecules on clay minerals, important constituents of tills, is a combination of different phenomena (Barshad 1955): hydration of exchangeable ions, adsorption on silicate surfaces, and intercalation between crystal layers. Ionic hydration, which is strongest at low humidities or in the BET region, is a saturating effect causing an isotherm of Langmuirian type. The other sorption steps add their own contributions to this, and the result is like a total isotherm of multilayer adsorption. Because of the composite nature of the sorption the computed monolayer capacity $n_{m}$ does not represent a real monolayer, but rather a formal point at the isotherm.

Authors differ in their opinions about suitability of water for surface area determinations. Odler and his coworkers (1972) claimed that nitrogen at low temperatures is unable to penetrate into small pores of hydrated Portland cement pastes: they recommended the use of water in such cases. Puri and Murari (1963) reported on reasonable specific areas of soils obtained by water adsorption. In contrast, Quirk (1955) remarked on the uncertainties associated with the areas of soils determined by water as adsorbate. In our opinion, the conditions of physical adsorption are not met with polar water molecules, and the obtained BET areas for tills are too high. The nitrogen adsorption areas, although perhaps too small in some cases, are generally more reliable. However, measuring the adsorption of water on soil samples is relevant, as it gives valuable information about the properties of soils in their natural environments.

Acknowledgements. We express our gratitude to Mrs. Tarja Salovaara and Mr. Arto Nieminen for their technical assistance in the measurements.

\section{References}

Adamson, A. W., 1976. Physical Chemistry of Surfaces, 3rd ed., Wiley, New York.

Barshad, I., 1955. Adsorptive and swelling properties of claywater system. Clays and Clay Technology, California Div. of Mines, Bull. 169, 70-77.

—, 1960. Thermodynamics of water adsorption and desorption on montmorillonite. Clays and Clay Minerals, Monograph No 8, 84-101.

Brunauer, S.; Emmett, P. H. \& Teller, E., 1938. Adsorption of gases in multimolecular layers. J. Am. Chem. Soc. 60, 
$309-319$.

Goldthwait, R. P., 1971. Introduction to till, today. Till a Symposium, Ed. Goldthwait, R. P Ohio State University Press, Columbus, pp. 3-26.

Gregg, S. J. \& Sing, K. S. W., 1967. Adsorption, surface area and porosity, Academic Press, London.

Gregor, H. P.; Sundheim, B. R.; Held, K. M. \& Waxman, $M$. $H .$, 1952. Studies on ion-exchange resins. V. Water vapor sorption. J. Colloid Sci. 7, 511-534.

Kellomäki, A., 1978. Adsorption of protium and deuterium oxides on cation exchange resins. Acta Chem. Scand. A $32,747-751$.

Nieminen, P. \& Kellomäki, A., 1982a. Adsorption of water on the fine fractions of tills. Report 9, Tampere University of Technology, Department of Civil Engineering, Engineering geology (in Finnish with English summary).

-, 1983b. Porosity of Finnish tills and clays. Report 10, Tampere University of Technology, Department of Civil Engineering, Engineering geology (in Finnish with English Summary).
Odler, I.; Hagymassy, J. JR.; Yudenfreund, M.; Hanna, K. M. \& Brunauer, S., 1972. Pore structure analysis by water vapor adsorption. IV. Analysis of hydrated Portland cement pastes of low porosity. J. Colloid and Interface Sci. $38,265-276$.

Orchiston, H. D., 1953. Adsorption of water vapor: I. Soils at $25^{\circ} \mathrm{C}$. Soil Sci. $76,453-465$.

,- 1954 . Adsorption of water vapor: II. Clays at $25^{\circ} \mathrm{C}$. Soil Sci 77, 463-480.

,- 1955 . Adsorption of water vapor: III. Homoionic montmorillonites at $25^{\circ} \mathrm{C}$. Soil Sci. $79,71-78$.

Puri, B. $R \&$ Murari, K., 1963. Studies in surface area measurements of soils. Soil Sci. 96, 331-336.

Quirk, J. P., 1955. Significance of surface areas calculated from water sorption isotherms by use of the B.E.T. equation. Soil Sci. 80, 423-429.

Stokes, R. H. \& Robinson, R. A., 1949. Standard solutions for humidity control at $25^{\circ} \mathrm{C}$. Ind. Eng. Chem. 41, 2013.

Manuscript received 18 . October, 1984 